\title{
IDENTIFICACIÓN DEL TIPO MORFOLÓGICO DE MICORRIZA ARBUSCULAR EN Phaeoceros laeVIs (Anthocerotophyta)
}

\author{
AGUSTINA C. COTTET* y MARÍA INÉS MESSUTI
}

\begin{abstract}
Summary: Morphological type identification of arbuscular mycorrhizal in Phaeoceros laevis (Anthocerotophyta). Arbuscular mycorrhizal have been registered for different representatives of Phylum Anthocerotophyta, including Phaeoceros laevis (L.) Prosk. In this paper we report the morphological type colonization by arbuscular mycorhyzal fungi in $P$. laevis, which corresponds to an intermediate between Arum-type and Paris-type. In addition, this association is mentioned for the first time for temperate forest of southern hemisphere. Brief descriptions and images of the characteristic structures of the arbuscular mycorrhiza present in $P$. laevis are presented.
\end{abstract}

Key words: Bryophytes, mycorrhizal association, southern hemisphere, temperate forest.

\begin{abstract}
Resumen: Las micorrizas arbusculares han sido registradas para distintos representantes del Phylum Anthocerotophyta, entre ellos Phaeoceros laevis (L.) Prosk. En este trabajo se da a conocer el tipo morfológico de colonización por parte de hongos micorrícicos arbusculares en $P$. laevis, el cual corresponde a un intermedio entre los tipos Arum y Paris. Además, esta asociación se menciona por primera vez para los bosques templados del hemisferio sur. Se presentan descripciones breves e imágenes de las estructuras características de las micorrizas arbusculares presentes en $P$. laevis.
\end{abstract}

Palabras clave: Asociación micorrícica, bosques templados, briófitos, hemisferio sur.

\section{INTRODUCCIÓN}

Las asociaciones que se establecen entre briófitos y hongos han sido documentadas por diversos autores, éstas pueden ser desde parasíticas hasta simbióticas formando micorrizas (Davey \& Currah, 2006; Liepina, 2012). Un ejemplo de esto, lo constituyen los representantes del filo Anthocerotophyta (antocerotes) que pueden formar simbiosis con hongos del subfilo Glomeromycotina (hongos micorrícicos arbusculares, HMA). La colonización de estos hongos en los talos de algunos antocerotes (e.g. Anthoceros, Folioceros, Notothylas, Phaeoceros y Phaeomegaceros) es abundante, ocasional (e.g. Megaceros y Nothoceros) o ausente (e.g. Dendroceros, Leiosporoceros) (Desirò et al., 2013). En particular, la asociación entre HMA y Phaeoceros laevis (L.) Prosk. ha sido estudiada bajo

1 INIBIOMA, CONICET-Universidad Nacional del Comahue, Quintral 1250, 8400 Bariloche, Argentina

*Autor para la correspondencia: agustina.c.cottet@gmail. com distintos aspectos que abarcan desde la ultraestructura de estos hongos hasta análisis moleculares y citológicos. Si bien la distribución de esta especie es cosmopolita, su relación con HMA fue registrada, hasta el momento, para un número reducido de regiones [China, Escocia, Gales, Inglaterra, Italia e Islas Malvinas (Falkland Islands)] (Ligrone, 1988; Desirò et al., 2013).

El objetivo de este trabajo es dar a conocer el tipo morfológico de colonización por parte de HMA en P. laevis y el primer registro de esta relación en los bosques templados del hemisferio sur.

\section{Material y Métodos}

\section{Área de estudio}

Los especímenes estudiados provienen de colecciones de diferentes sitios del bosque templado realizadas al oeste de las provincias de Río Negro y Chubut (BCRU 5491-5495) los que fueron depositados en el herbario BCRU. 


\section{Colección e identificación de P. laevis}

Los ejemplares fueron coleccionados, herborizados e identificados empleando las técnicas tradicionales para el estudio de los briófitos (Frahm, 2003). Para la identificación se siguieron los criterios propuestos por Hässel de Menéndez (1962) y Gradstein \& Da Costa (2003).

\section{Observación de estructuras de HMA}

Los gametofitos fueron lavados con agua corriente y preservados en etanol $70 \%$ durante 24 horas a temperatura ambiente; luego de este periodo fueron colocados a $50^{\circ} \mathrm{C}$ hasta la evaporación total del líquido. Posteriormente, fueron clarificados en hidróxido de potasio $1 \%$ durante 20 minutos a $80^{\circ} \mathrm{C}$; acidificados con ácido clorhídrico $1 \%$ durante 10 minutos a $50^{\circ} \mathrm{C}$ y teñidos con azul tripán $0,05 \%$ durante 20 minutos a $60^{\circ} \mathrm{C}$. Para observar las estructuras características de los HMA, se montaron cinco fragmentos ( $c a .2 \mathrm{~cm}$ de largo) por gametofito en lactofenol de Amman, los que fueron examinados con microscopio óptico.

\section{Resultados}

Los gametofitos de P. laevis observados son verdes oscuros, gregarios y adheridos al sustrato por rizoides unicelulares. En corte transversal, la superficie dorsal es plana a levemente curvada y lisa; el talo es sólido con el tejido fundamental sin cavernas, con colonias de Nostoc sp. y la superficie ventral es convexa o aquillada.

La colonización de los HMA se evidenció por la presencia de estructuras fúngicas características. Se observaron hifas aseptadas, principalmente en la porción media del talo, tanto en la superficie como en su porción interna. Las hifas superficiales o externas cercanas a los rizoides miden $c a$. $6,5 \mu \mathrm{m}$ de diámetro. Mientras que las internas, localizadas en el espacio intercelular de las células parenquimatosas, miden ca. 2,5 $\mu \mathrm{m}$ de diámetro. Tanto los arbúsculos como las hifas replegadas formando circunvoluciones son intracelulares y abundantes en la porción media del talo. Los primeros miden $c a .35$ x $30 \mu \mathrm{m}$ y las hifas que los conforman presentan un rango entre 0,4-4 $\mu \mathrm{m}$ de diámetro, siendo más pequeñas hacia los ápices de los arbúsculos (Fig. 1 A). Las hifas replegadas formando circunvoluciones miden $5 \mu \mathrm{m}$ de diámetro (Fig. 1 B). Por el contrario, las vesículas son escasas y miden $c a .45$ x 27,5 $\mu \mathrm{m}$ (Fig. 1 C).

\section{Discusión y Conclusiones}

Algunos antocerotes pueden establecer relaciones simbióticas duales con representantes de los subfilos Glomeromycotina y Mucoromycotina

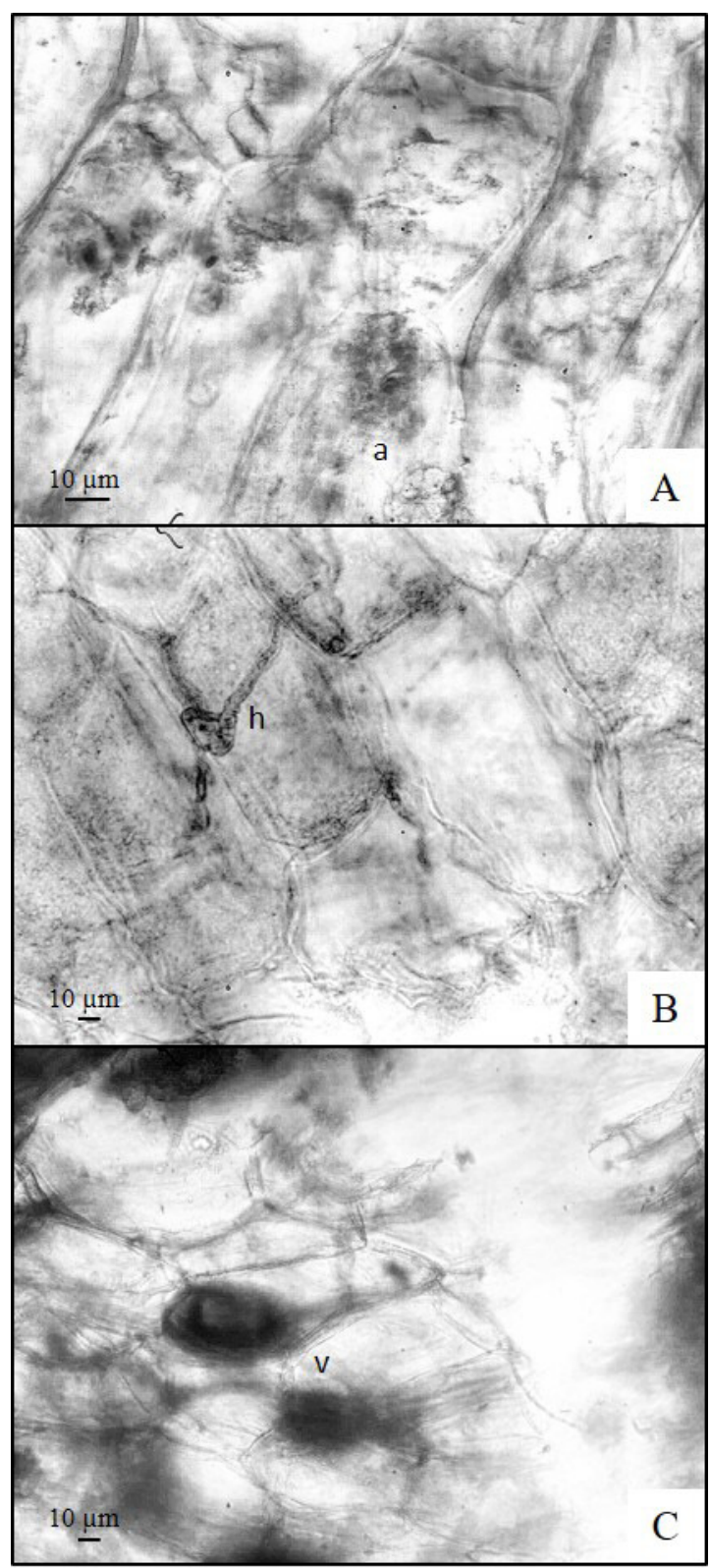

Fig. 1. Colonización micorrícica arbuscular del tipo Intermediate 1 en Phaeoceros laevis (L.) Prosk. (BCRU 5491). A: Arbúsculos (a). B: Hifas replegadas formando circunvoluciones (h). C: Vesícula (v). 


\section{A. Cottet y M. I. Messuti - Micorrizas arbusculares en Phaeorceros laevis}

(Desirò et al., 2013). Sin embargo, a pesar de sus similitudes morfológicas se pueden diferenciar por la formación de vesículas vs. la ausencia de estas; tener hifas de los arbúsculos con rango de diámetro entre 1-3 $\mu \mathrm{m}$ vs. 0,5-1 $\mu \mathrm{m}$; e hifas principales de 4-8 $\mu \mathrm{m}$ de diámetro $v s$. 3-4 $\mu \mathrm{m}$ (Field et al., 2016). En particular, la relación que se establece entre $P$. laevis y los HMA ya ha sido mencionada con anterioridad por otros autores como Ligrone (1988) y Desirò et al. (2013), donde ninguno ha definido el tipo morfológico de colonización por parte de estos hongos. Sin embargo, a partir de nuestras observaciones este último puede ser definido, en condiciones naturales, como un tipo morfológico intermedio entre Arum y Paris. Siguiendo la clasificación de los tipos de colonización de HMA propuesta por Dickson (2004) este corresponde al tipo denominado Intermediate 1, el que se caracteriza por la presencia de arbúsculos intracelulares formados a partir de hifas intercelulares e hifas intracelulares. Por otra parte, se han encontrado diferencias en relación al tamaño de las estructuras fúngicas según lo mencionado por Ligrone (1988) y el material estudiado (BCRU 5491-5495): hifas extracelulares $(4 \mu \mathrm{m} v s .6,5 \mu \mathrm{m})$; hifas intercelulares $(4,5 \mu \mathrm{m} v s$. $2,5 \mu \mathrm{m})$; hifas intracelulares $(2,3 \mu \mathrm{m} v s .2,7 \mu \mathrm{m}) \mathrm{y}$ vesículas $(22,5 \mu \mathrm{m} v s .27,5 \mu \mathrm{m})$. Además, en este trabajo se menciona por primera vez la presencia de esta relación en los bosques templados del hemisferio sur.

\section{Agradecimientos}

Los autores agradecen a la Administración de Parques Nacionales por los permisos de colección y la amabilidad de todos los guardaparques. Este trabajo fue financiado por el Consejo Nacional de Investigaciones Científicas y Tecnológicas (CONICET) y por la Universidad Nacional del Comahue (UNComahue).

\section{Bibliografía}

DAVEY, M. L. \& R. S. CURRAH. 2006. Interaction between mosses (Bryophyta) and fungi. Canad. J. Bot. 84: 1509-1519.

DESIRÒ A., J. G. DUCKETT, S. PRESSEL, J. C. VILLARREAL \& M. I. BIDARTONDO. 2013 Fungal symbioses in hornworts: a chequered history. Proc. R. Soc. B. 280: 20130207.

DICKSON, S. 2004. The Arum-Paris continuum of mycorrhizal symbioses. New Phytol. 163: 187-200.

FRAHM, J. P. 2003. Manual of tropical bryology. Trop. Bryol. 23: 1-200.

FIELD, K. J., W. R. RIMINGTON, M. I. BIDARTONDO, K. ALLINSON, D. J. BEERLING, D. D. CAMERON, J. G. DUCKETT, J. R. LEAKE \& S. PRESSEL. 2016. Functional analysis of liverworts in dual simbiosis with Glomeromycota and Mucoromycotina fungi under a simulated Palaeozoic $\mathrm{CO}_{2}$ decline. ISME J. 10: 1514-1526.

GRADSTEIN, S. R. \& D. PINEHIRO DA COSTA. 2003. The Hepaticaea and Anthocerotae of Brazil. Mem. N. Y. Bot. Gard. 87: 1-318

HÄSSEL DE MENÉNDEZ, G. G. 1962. Estudio de las Anthocerotales y Marchantiales de la Argentina. Opera Lilloana 7: 1-297.

LIEPINA, L. 2012. Occurrence of fungal structures in bryophytes of the boreo-nemoral zone. Environ. Exper. Bot. 10: 35-40.

LIGRONE, R. 1988. Ultrastructure of a fungal endophyte in Phaeoceros laevis (L.) Prosk. (Anthocerophyta). Bot. Gaz. 149: 92-100.

Recibido el 20 de febrero de 2017, aceptado el 8 de mayo de 2017. 
